\title{
De la democracia participativa al gobierno abierto: hacia una delimitación conceptual
} From participatory democracy to open government: towards a conceptual delimitation

DOI: http://dx.doi.org/10.29105/pgc4.7-1

Carlos Gómez Díaz de León ${ }^{1}$

Universidad Autónoma de Nuevo León

https://orcid.org/0000-0001-6796-5569

\section{RESUMEN}

El presente artículo es producto de una revisión bibliográfica, cuyo objetivo consistió en reflexionar sobre el concepto de democracia como una forma de participación política de la sociedad en su conjunto. Se aplicó el método de análisis, con un enfoque cualitativo, diseño no experimental, bajo un nivel documental-bibliográfico transversal. Tras la revisión documental se encontró que: debido a las profundas transformaciones que se viven a nivel mundial producto de los distintos movimientos sociales, políticos y económicos, inducen a la reflexión serena y aguda sobre las mejores formas de organizar las instituciones gubernamentales y sobre todo el papel del ciudadano en los sistemas políticos. Se concluye que las transformaciones económicas, sociales y tecnológicas han provocado reformas trascendentales en el modelo de gobierno, afectando de esta manera el funcionamiento de las democracias modernas.

Palabras clave: Democracia, Gobierno, Gobierno Abierto, Legitimidad Democrática, Participación Ciudadana.

\section{ABSTRACT}

This article is the product of a literature review, which objective was to reflect on the concept of democracy as a form of political participation of society as a whole. The method of analysis was applied, with a qualitative approach, non-experimental design, under a transversal documentary-bibliographic level. After the documentary review, it was found that: due to the profound transformations that are experienced worldwide as a result of the different social, political and economic movements, they induce a serene and acute reflection on the best ways to organize government institutions and especially the citizen's role in political systems. It is concluded that the economic, social and technological transformations have caused transcendental reforms in the government model, thus affecting the functioning of modern democracies.

Key words: Democracy, government, open government, democratic legitimacy, citizen participation.

Cómo referenciar este artículo:

Gómez Díaz, C. (2018). De la Democracia participativa al Gobierno Abierto: hacia una delimitación conceptual. Revista Política, Globalidad y Ciudadanía, 14-30. Recuperado de http://revpoliticas.uanl.mx/index.php/RPGyC/ article/view/86

Recibido: 05 de Julio 2017 - Aceptado: 30 de Agosto 2017

\section{(cc) EY-NC-ND}

1 Doctorado en Derecho Público en Sceaux Francia, Docente Investigador en la Facultad de Ciencias Políticas y Administración Publica, Universidad Autónoma de Nuevo León. Correo electrónico: dr.cgomez56@gmail.com

Revista Política, Globalidad y Ciudadanía, Vol. 4 No. 7, Enero - Junio 2018, Universidad Autónoma de Nuevo León, Monterrey, México, ISSN 2395-8448. pp 14-30. http://revpoliticas.uanl.mx/index.php/RPGyC/article/view/86 


\section{INTRODUCCIÓN}

Desde los tiempos más remotos de la historia de la humanidad los hombres se han preocupado por organizar su comunidad a fin de decidir sobre los aspectos que conciernen a todos, a la colectividad. Esta actividad es precisamente lo que conocemos como política; la sociedad se organiza por medio del gobierno, y de acuerdo con los teóricos y filósofos de la ciencia política, la mejor forma de participar en este proceso ha sido la democracia.

Muy probablemente ningún otro concepto haya sido tan analizado en la historia de la teoría y la filosofía política como este último concepto, la democracia. En efecto, a pesar de contar con más de dos siglos y medio de existencia como categoría social y de una experiencia efímera en la antigua Grecia, la democracia sigue siendo hoy, en pleno siglo XXI objeto de debates y controversias entre politólogos y académicos sociales que tratan de explicar sus condiciones, características, valores, medios, contextos, etc. Sin lugar a dudas es lícito afirmar que la democracia se ha convertido en el modelo moderno de sistema de gobierno por excelencia.

El proceso de desarrollo histórico del concepto desde la acuñación del concepto por parte de los antiguos griegos ha venido renovando su significado llevándola a diversos momentos y características que han dado lugar a calificativos que pueden ser contrastados y que revisten una connotación muy diversa. Desde las célebres clasificaciones de Aristóteles de las distintas formas de gobierno, pasando por Maquiavelo clasificación de las formas de organización de los Estados, y con la caracterización de la democracia que nos ofrece Tocqueville, hasta la identificación de las condiciones actuales que conforman los modelos democráticos modernos (Sartori, 2008; Bobbio, 2000; Cerroni, 1997, entre otros filósofos políticos recientes). Por eso, como bien lo señala Bovero de una forma muy original y analógica (2002), en la era moderna del concepto y para su construcción teórica y empírica es necesario agotar su "gramática", y podemos pasar de los sustantivos o la cosa por definir, a los adjetivos, es decir a los calificativos o modalidades, y de éstos a los verbos de la democracia, es decir las dinámicas que involucra, y con ello no agotaríamos los diversos ángulos bajo los cuales puede analizarse esta institución.

Por lo anteriormente expuesto, el tema resulta de especial interés en momentos en que se están viviendo profundas transformaciones a nivel mundial producto de movimientos sociales, económicos y políticos que inducen a la reflexión serena y aguda sobre las mejores formas de organizar las instituciones gubernamentales y sobre todo el papel del ciudadano en los sistemas políticos. Esto último en razón de la potencialización que han dado a la participación ciudadana dos fenómenos estrechamente relacionados y que afectan directamente el funcionamiento y la dinámica gubernamental. Primeramente, el vertiginoso desarrollo tecnológico del sector de telecomunicaciones, información digital, ingeniería artificial, robótica, entre otros aspectos. Desde la perspectiva de la comunicación y la información este extraordinario desarrollo ofrece una ventana de interacción entre el gobierno y el ciudadano que incluso se convierte en un desafío por la necesidad de su adecuada regulación y uso mesurado. En segundo lugar, desde la perspectiva de la sociedad civil, la emergencia de las redes sociales como consecuencia del desarrollo tecnológica arriba mencionado, proporciona mayores espacios de comunicación, reflexión, organización e intervención de la ciudadanía en los asuntos públicos.

En este contexto, la categoría gobierno también se ha visto influenciada por los vertiginosos cambios en el entorno global y local en función de las exigencias ciudadanas de mayor eficacia, calidad y posibilidades de participación en los procesos deliberativos de las políticas públicas. Como veremos en este trabajo la categoría ha llegado a su punto más actual con la caracterización del Gobierno Abierto. Se identifica como un modelo de gestión (Mariñez Navarro, 2013, pág. 42); implica un conjunto de cambios en la perspectiva de la cultura organizacional y de gestión. Con la interacción de sus elementos rectores que son la transparencia, la participación y la colaboración, y su plataforma que son las tecnologías de la información, el

Revista Política, Globalidad y Ciudadanía, Vol. 4 No. 7, Enero - Junio 2018, Universidad Autónoma de Nuevo León, Monterrey, México, ISSN 2395-8448. pp 14-30. http://revpoliticas.uanl.mx/index.php/RPGyC/article/view/86 
gobierno abierto se ha convertido en una nueva forma de fortalecimiento de las capacidades del gobierno y la modernización de la administración pública (Mariñez Navarro, pág. 43).

La crisis gubernamental en términos de eficiencia, eficacia y legitimidad (Cabrero: 1997), va conformando condiciones de ingobernabilidad en las cuales se ponen en entredicho las capacidades gubernamentales para dirigir y dar cumplimiento a los objetivos del Estado en términos de progreso, estabilidad y paz social. Es por ello que a partir del último tercio del siglo XX aparece el concepto de gobernabilidad y en la última década como una extensión de éste los analistas y académicos han acuñado el término gobernanza apelando a una nueva forma de gobernar a la sociedad con la sociedad. Si a ello añadimos el espectacular desarrollo tecnológico de las telecomunicaciones y en general de las tecnologías de la información y comunicación (TIC'S), ello ha contribuido a revitalizar un concepto referido a esta colaboración entre ciudadano y gobierno, por un lado, y la utilización de las tics para fomentar, mejorar y hacer eficiente el proceso de gobierno, por otro, con lo cual aparece el concepto o más bien categoría social de Gobierno Abierto. En esta forma, se articula una relación muy estrecha entre los elementos del modelo democrático con los paradigmas que las nuevas tecnologías abren a las reformas del Estado moderno y en particular desde la perspectiva de la participación.

En este marco general, en el presente trabajo partiremos del análisis teórico de los elementos de la democracia moderna a partir de los postulados de Tocqueville y que conforman el centro de la teoría democrática liberal es decir la igualdad y la libertad, para ir explicando su derivación al modelo representativo y posteriormente su gradual transformación hacia el gobierno abierto. Para ello analizaremos también los postulados del régimen de derecho que garantiza el modelo democrático y todo el entramado institucional que da el marco normativo al proceso de gobierno acorde a la estructura institucional de la división de poderes propuesta por la teoría clásica de Montesquieu.

Metodológicamente, desde un enfoque cualitativo se utilizará el análisis discursivo a partir de los textos de Tocqueville, Bobbio, Bovero, Cerroni, Sartori y algunos clásicos de la ilustración francesa. Para ello se discurrirá sobre la evolución de la democracia directa hacia la democracia representativa hasta analizar las características de los alcances que tiene el gobierno abierto desde la perspectiva democrática. El punto central del análisis será la participación como un componente indispensable del modelo democrático y su legitimidad como factor de permanencia. La hipótesis del trabajo plantea que, a través de la participación colaborativa del ciudadano en la gestión pública, el Gobierno Abierto se convierte en un elemento revitalizador de la democracia en este siglo XXI. Específicamente, partimos de la premisa que la fortaleza y la funcionalidad del acceso a la información como derecho ciudadano, de la transparencia como política pública, de la rendición de cuentas como mecanismo de responsabilización, y la colaboración como característica funcional, constituyen las bases de una administración abierta y de un gobierno democrático fundado en el Estado de derecho.

\section{2.- FUNDAMENTO TEÓRICO}

\section{La democracia de Tocqueville}

Para propósitos del presente trabajo, partiremos de la noción de democracia que nos ofrece uno de los autores que con mayor lucidez y al mismo tiempo simplicidad ha estudiado el modelo democrático. Sobre una metodología comparativa y empírica, Alexis de Tocqueville nos ofrece un retrato inigualable de la democracia como sistema de gobierno al describir el sistema político norteamericano. La base sobre la cual se genera según este autor el modelo democrático es la igualdad de condiciones (Tocqueville, 2012, pág. 31). Considera que el desarrollo de esta cualidad además de ser providencial tiene las siguientes características: "universal, durable, que escapa a la potestad humana y todos los acontecimientos, como todos los hombres, sirven para su desarrollo" (pág. 33). Si bien considera también a la libertad como un valor intrínseco a la

\footnotetext{
Revista Política, Globalidad y Ciudadanía, Vol. 4 No. 7, Enero - Junio 2018, Universidad Autónoma de Nuevo León, Monterrey,
} México, ISSN 2395-8448. pp 14-30. http://revpoliticas.uanl.mx/index.php/RPGyC/article/view/86 
democracia, la subordina a la igualdad como producto precisamente de ese factor generador que es la igualdad de condiciones. Esto lo explica magistralmente al ponderar la igualdad versus la libertad en la segunda parte del segundo volumen de su obra al expresar: "No difiriendo entonces ninguno de sus semejantes, nadie podrá ejercer un poder tiránico, pues en este caso, los hombres serán perfectamente libres, porque serán del todo iguales, y perfectamente iguales porque serán del todo libres, siendo este el objeto ideal hacia el cual propenden siempre los pueblos democráticos" (pág. 463). Para complementar el modelo, Tocqueville coincide con sus contemporáneos (Rousseau y Montesquieu) en el sentido que la soberanía reside en el pueblo y nos explica los principios de representación y del gobierno de la mayoría. En Norteamérica nos dice este autor, "el pueblo nombra a quien hace la ley y a quien la ejecuta (...) nombra directamente a sus representantes y los escoge cada año, a fin de tenerlos completamente bajo su dependencia", también integra los jurados que castigan las infracciones a la ley, y finalmente concluye, "la mayoría es la que gobierna en nombre del pueblo" (pág. 191). En este breve análisis incluye los tres poderes que constituyen la base del modelo democrático sustentado en la división de poderes propuesto por Montesquieu Con estos elementos conceptuales ofrecidos por Tocqueville se construyen los argumentos y estudios que han conformado la teoría democrática identificada como formal en los debates modernos sobre la democracia y que veremos con más detalle en el siguiente apartado.

\section{De la democracia formal a una democracia representativa}

En la historia del pensamiento político la democracia se ha convertido en el valor ideal de las formas de gobierno modernas. A pesar de algunas críticas derivadas de visiones limitadas, las cuales sin lugar a dudas no tienen fundamentación sólida, ya que consideran que esta forma de gobierno nacida en la tradición teórica occidental de la antigua Grecia no es aplicable en ciertos contextos como es el caso de las culturas orientales y de países pobres, en los cuales este sistema ha tenido un desempeño más deficiente que los regímenes autoritarios (Sen: 2007), el modelo democrático es el "menos peor de los regímenes políticos", o de manera positiva la mejor forma de gobierno y organización política y social.

Desde la perspectiva de la teoría clásica de la democracia liberal (Bobbio, 2002; Sartori, 2008), los sistemas políticos modernos y que además pueden caracterizarse como democráticos están sustentados en dos sólidos pilares: en primer lugar, un conjunto de normas jurídicas que regulan el funcionamiento orgánico del sistema, así como las relaciones necesarias entre los actores participantes en el juego político. Esto constituye precisamente el régimen de derecho que se constituye en la piedra angular del sistema.

En segundo lugar, ante la imposibilidad de que la sociedad en su totalidad, es decir de que todos y cada uno de los individuos integrantes de la comunidad política puedan participar directamente en las decisiones públicas, aparece la institución de la representación como un componente fundamental de las democracias modernas y que permite un funcionamiento relativamente ágil y eficaz del sistema político.

Así, la democracia se construye a partir de un sistema institucional y complejo de separaciones y equilibrios entre poderes, un entramado de límites y vínculos a su ejercicio, de garantías establecidas para la tutela de los derechos fundamentales, de técnicas de control y reparación frente a sus violaciones y de una continua comunicación entre autoridad y ciudadano que vitaliza la legitimidad del proceso de gobierno.

Este complejo sistema de vínculos y equilibrios, desde la perspectiva formal, no es otra cosa que el régimen de derecho en sentido restringido. En sentido amplio esta ingeniería institucional es el marco constitucional que regula el funcionamiento de las instituciones públicas y que se convierte en la garantía fundamental de la democracia y desde el punto de vista sustancial, es decir como sistema de derechos fundamentales establecidos frente a cualquier tentación despótica en el ejercicio del poder, en garantía de la igualdad y de la representación de las necesidades de todos. 
En palabras de Cerroni (1991) estos procedimientos y controles establecidos como garantía de la representación y del principio de la mayoría integran las reglas de la democracia moderna. Junto a estas dos reglas encontramos las referidas a otros elementos constitutivos del juego democrático:

- Regla del consenso: condición sine qua non; es la institucionalización de la confrontación pública, a través de la cual las opiniones y las preferencias dejan de ser idiosincrasia privada, pueden matizarse, corregirse y modelarse por acción recíproca, converger y reagruparse, y de esta manera constituir la base de decisiones (públicas) ponderadas.

- Regla de la competencia: confrontación de opiniones y competidores

- Regla de la mayoría: ninguna decisión tomada por la mayoría debe limitar los derechos de las minorías

- Regla de la minoría: posibilidad de alternancia

- Regla del control: poder controlable

- Regla de la legalidad: sin violencia

- Regla de la responsabilidad: cada uno es responsable de conformar la voluntad general, el interés público, sacrificando otros intereses.

En esta forma, el modelo democrático procesal-formal se estructura normativamente mediante este conjunto de reglas, pero no logra asegurar la participación efectiva de amplios grupos de la sociedad en la toma de decisiones. Por ello es necesario encontrar fórmulas que fomenten esa participación ciudadana a través de mecanismos y canales plurales y abiertos a la expresión de la ciudadanía. Es a través del capital social que se legitima el régimen al incorporar a la sociedad civil en los objetivos sociales comunitarios.

Por otra parte, en estrecha relación con el tema de la participación, desde la evolución de la teoría institucional se va conformando un marco teórico sobre la importancia de las relaciones, las normas y los valores $^{2}$ en los procesos de desarrollo democrático y va construyéndose la noción de capital social (Kliksberg: 2004) y sus implicaciones sobre las políticas públicas, sobre todo en las orientadas hacia la lucha contra la desigualdad, la pobreza y la marginalidad. El sustrato esencial de esta noción son las relaciones que derivan de la participación de los individuos y grupos en objetivos comunes. Es precisamente a partir de esos objetivos comunes que podemos incorporar este concepto de capital social a nuestro análisis político.

Con base en estos tres componentes, democracia, capital social y participación, constituyen los principales fundamentos teóricos de cada uno de estos constructos sociales y se trata de vincularlos en la búsqueda de un modelo que articule la participación ciudadana para lograr las metas del desarrollo democrático.

De la democracia representativa a la democracia participativa.

En este marco conceptual, debemos de entender por régimen democrático un conjunto de reglas procesales para la toma de decisiones colectivas en el que está prevista y propiciada la más amplia participación posible de los interesados (Bobbio, 1984). Estas reglas establecen: quién está autorizado a tomar las decisiones colectivas y, bajo qué procedimientos. Respecto de la modalidad de decisión, la regla básica de la democracia es la regla de la mayoría.

Es necesario que los representantes, es decir, aquellos llamados a tomar decisiones o que seleccionen a quiénes van a tomar las decisiones, cuenten con alternativas reales y estén en condiciones de elegir entre unas y otras. Quienes deciden deben tener garantizados los derechos de opinión, expresión, reunión, asociación, etc. (los derechos "inviolables" del individuo).

2 Entre estos valores destacan: confianza, reciprocidad, asociavitidad, civismo, ética.

Revista Política, Globalidad y Ciudadanía, Vol. 4 No. 7, Enero - Junio 2018, Universidad Autónoma de Nuevo León, Monterrey, México, ISSN 2395-8448. pp 14-30. http://revpoliticas.uanl.mx/index.php/RPGyC/article/view/86 
Por otra parte, según Robert Dahl (1999: p. 47), existen cinco criterios que un gobierno democrático debe satisfacer a fin de asegurar que todos los miembros de la sociedad sean políticamente iguales: 1) Participación efectiva; 2) Igualdad de voto; 3) Alcanzar una comprensión ilustrada; 4) Ejercitar el control final sobre la agenda; 5) Inclusión de los adultos.

A su vez, la satisfacción de estos estándares exige un sistema institucional que cumpla con ciertas características: primero, que esté a cargo de representantes electos; segundo que garantice elecciones libres, limpias y frecuentes; tercero que garantice la libertad de expresión; cuarto que provea información alternativa; quinto que permita la libertad y la autonomía asociativa; y, sexto, que incluya en la ciudadanía a la totalidad de los adultos.

Sin embargo, desde la perspectiva de O'Donnell, las modernas democracias son democracias en el sentido de que cumplen con los criterios de Robert Dahl antes mencionados, pero no son democracias representativas y menos aún participativas, por lo que las denomina democracias delegativas. Este tipo de democracias las concibe más bien como una disfunción de la democracia ante la falta de representatividad de los intereses colectivos, así como de un control efectivo sobre ellos, con lo que busca expresar una forma de gobierno autoritaria legitimada a través de elecciones democráticas, en el marco de una estructura administrativa autoritaria. Del planteamiento de Dahl llama la atención su reiterada insistencia por el control de la agenda pública por parte de la ciudadanía como un mecanismo de ajuste permanente para garantizar la efectiva representatividad de los intereses de la sociedad. Por ello insiste en revisar y controlar ciertos aspectos a fin de reducir los riesgos de la degeneración a un sistema oligárquico. Estos son: 1) La estabilización de las desigualdades sociales; 2) la deformación de la conciencia cívica; 3 ) la distorsión de la agenda pública y, 4) la usurpación del control final sobre la política.

Como podemos apreciar, estas ideas nos advierten las limitaciones del enfoque reduccionista de la democracia a elecciones y votos. Además, se circunscribe al ámbito político.

Superando este enfoque formalista, Bobbio, afirma que la democracia representativa quiere decir que las deliberaciones colectivas, es decir, las deliberaciones que involucran a toda la colectividad no son tomadas directamente por quienes forman parte de ella, sino por personas elegidas para este fin. De esta forma, en un Estado representativo, las principales deliberaciones políticas son realizadas por los representantes elegidos, en este caso, el titular del Poder Ejecutivo y los representantes en el Poder Legislativo, tanto en el ámbito federal, como estatal y municipal. No obstante, Bobbio (1986) considera que una de las tareas pendientes de la democracia es rebasar el ámbito estrictamente político y trascender a los espacios empresariales y de los aparatos administrativos. El desarrollo de la democracia debe medirse a partir del incremento no tanto de los que tienen derecho a participar sino de los espacios para la participación. Es aquí donde se abre la ventana del gobierno abierto como condicionante del desarrollo democrático. Mientras en los dos grandes sectores de poder que caracterizan a las sociedades avanzadas, a saber, las empresas y el aparato administrativo, no se vean procesos democráticos en los cuales se tengan espacios de participación, la democracia estará muy limitada. Esa es la oportunidad que ofrece el Gobierno Abierto.

Guillermo O’Donnell señala que la representación implica, por un lado, el reconocimiento del derecho de los representantes de hablar en nombre de los que dicen representar y, por otro lado, la capacidad de los representantes de lograr que los representados concuerden habitualmente con lo que ellos deciden.

Las democracias representativas que nosotros conocemos son democracias en las que por representante se entiende una persona que tiene las siguientes características:

- En cuanto goza de la confianza del cuerpo electoral, una vez elegido ya no es responsable frente a sus electores y en consecuencia no es revocable;

Revista Política, Globalidad y Ciudadanía, Vol. 4 No. 7, Enero - Junio 2018, Universidad Autónoma de Nuevo León, Monterrey, México, ISSN 2395-8448. pp 14-30. http://revpoliticas.uanl.mx/index.php/RPGyC/article/view/86 
- No es responsable directamente frente a sus electores, precisamente porque él está llamado a tutelar los intereses generales de la sociedad civil y no los intereses particulares de esta o aquella profesión.

Por su parte, como mencionamos más arriba, Bovero identifica cuatro verbos o acciones típicas a través de los cuales se desarrolla el juego democrático, es decir, el funcionamiento de la democracia. Uno de ellos es "representar". La representación puede ser considerada democrática sólo cuando los órganos representativos reflejan las diversas tendencias políticas de los ciudadanos sin exclusiones y en las proporciones representativas.

No obstante, Bobbio se refiere a la representación como una de "las promesas incumplidas de la democracia”, ya que afirma que la norma constitucional según la cual los legisladores serán los representantes de la nación en su conjunto y no de grupos de interés particular es el más violado de todos los principios. Esto en razón de que en las decisiones se atiende a los intereses corporativos y/o particulares y no al interés general.

En el pensamiento de Bovero, así como más expresamente en el de Rawls, lo fundamental es el debate, es decir que la democracia debe verse en términos de razonamiento público, con la debida oportunidad del debate público, así como de la participación interactiva y del encuentro razonado. Sin embargo, este razonamiento está sustentado en ciertas exigencias sociales que contribuyan al discernimiento objetivo y justo, tales como la incorporación de información pertinente, la pluralidad de puntos de vista, discusiones y debates públicos y abiertos. Solo así se logra el razonamiento constructivo y eficaz (Sen: p. 45). Por eso, el modelo participativo del capital social que es el que se adopta en este trabajo, se inserta mucho más en la visión comunitarita y neo republicana de la democracia que subraya la inclusión de la sociedad civil en la toma de decisiones colectivas que ofrece Taylor (Aguilera: p. 61).

En esta visión, "la noción de sociedad civil comprende la multitud de asociaciones libres que existen fuera del patrocinio oficial y que con frecuencia están dedicadas a propósitos considerados generalmente no políticos. Ninguna sociedad puede considerarse libre si no permite el funcionamiento de estas organizaciones voluntarias". Así, la categoría de ciudadano está determinada por el grado de compromiso con la participación en el espacio público con fundamento en valores, deberes y virtudes sociales, tales como la solidaridad, la justicia social, la equidad y la igualdad formal y material.

En este marco, consideramos que el modelo de democracia participativa y su vinculación con el capital social se fundamenta desde tres argumentaciones: primero en la postura de ciudadanía de Marshall y de la Carta de Derechos y deberes del ciudadano de 1948, en segundo término, en la propuesta de democracia participativa de Dewey y por último en considerar a la participación ciudadana como fuente de legitimidad democrática. A continuación, ampliaremos brevemente estas argumentaciones.

La participación política: una responsabilidad ciudadana

El concepto de ciudadanía está estrechamente relacionado con el de democracia. De hecho, es consustancial a la democracia, es decir que no se puede concebir una democracia sin ciudadanos. En este orden de ideas, la crisis de la democracia se debe a un déficit de ciudadanía. Así lo sentencia Victoria Camps (2010: p. 10) cuando afirma que "las democracias liberales adolecen de capital social, los ciudadanos no viven cohesionados y no se sienten motivados para hacerse cargo de unas obligaciones que conciernen a todos". Desde la perspectiva histórica, la construcción de la ciudadanía se ha acompañado de la conquista y evolución gradual de los derechos fundamentales, que según Thomas Marshall (1997) pasó de los derechos civiles a los derechos políticos y después a los derechos sociales. 
De acuerdo con la categorización que nos ofrece Marshall al integrar el concepto de ciudadanía con tres elementos: el civil, el político y el social. El elemento civil consiste en los derechos necesarios para gozar de la libertad individual (libertad de la persona, libertad de expresión, de pensamiento y de religión, el derecho a la propiedad, a cerrar contratos válidos, y el derecho a la justicia). Esta libertad se ejerce en el continuo intercambio que los individuos realizan entre sí y que corresponden fundamentalmente al ámbito privado.

Con respecto al elemento político, si bien Marshall se refiere al derecho a participar en el ejercicio del poder político como miembro de un cuerpo investido de autoridad política, o como electo de los miembros de tal cuerpo; podemos decir, que hoy en día existen muchas otras formas de participación ciudadana, ya sean formales o informales, mediante las cuales se puede incidir directa o indirectamente en los asuntos públicos, sin que ésta se reduzca al fenómeno electoral, es decir a la emisión del sufragio. En efecto, podemos afirmar que se ha venido ampliando el radio de la participación dando lugar incluso a lo que se ha denominado gobierno abierto. De ello discutiremos más adelante.

Por su parte, el elemento social se refiere a todo el conjunto de prerrogativas que van desde el derecho a un mínimo de bienestar económico y seguridad, hasta llegar a considerar el derecho a participar del patrimonio social y al vivir de un ser civilizado conforme a los estándares corrientes en la sociedad.

Sin embargo, según Jordi Borja (2002), los derechos que configuran la ciudadanía en nuestros días son mucho más complejos que en el pasado y se tienen que adecuar a poblaciones y exigencias sociales mucho más diversificadas e individualizadas. Este autor señala que la construcción histórica de la ciudadanía obedeció a dos procesos fundamentales: por una parte, a la ampliación de los derechos formales de las personas y por otra parte, al desarrollo de los contenidos reales de los derechos mediante políticas públicas que redujeran las desigualdades sociales y culturales, sin las cuales, los derechos políticos son formales y ficticios, lo cual supone dar contenidos materiales a los derechos teóricos, ampliando incluso su formulación inicial y añadiendo nuevos derechos.

En la actualidad, la globalización nos exige establecer cartas de derechos universales, estructuras representativas de regulación y participación en ámbitos supra estatales y políticas públicas que garanticen estos derechos en los distintos ámbitos, a saber: en contextos internacionales, nacionales y locales.

Esta idea la Organización de las Naciones Unidas (ONU) la consagró en la Declaración Universal de los Derechos Humanos y particularmente del artículo 29:

- Toda persona tiene deberes respecto a la comunidad puesto que sólo en ella puede desarrollar libre y plenamente su personalidad.

- 2En el ejercicio de sus derechos y en el disfrute de sus libertades, toda persona estará solamente sujeta a las limitaciones establecidas por la ley con el único fin de asegurar el reconocimiento y el respeto de los derechos y libertades de los demás, y de satisfacer las justas exigencias de la moral, del orden público y del bienestar general en una sociedad democrática.

De esta forma vemos que los derechos no vienen solos, sino más bien como dice Borja (2002), la ciudadanía es un concepto dialéctico entre derechos y deberes, ya que todos los derechos comportan evidentemente los deberes correspondientes por parte de sus titulares, sin lo cual los derechos pierden eficacia para el conjunto de la ciudadanía. En la misma dirección, Puyol (2010: p. 55) apunta que el ciudadano es sujeto de deberes y obligaciones que le vinculan a la vida colectiva y lo comprometen a una visión política con cierta institucionalidad, y con contenido de justicia social.

En este sentido, le corresponde al Estado como máxima instancia de articulación social, garantizar el 
pleno ejercicio de los derechos fundamentales. Por ello, para efectos de este trabajo centraremos nuestra atención en el ejercicio de los derechos civiles y políticos, específicamente en el derecho de participación como un elemento fundamental de la democracia como afirma Víctor Abramovich (2006), que al mismo tiempo permita alcanzar los derechos sociales como componentes fundamentales del desarrollo democrático.

\section{La educación cívica y la democracia participativa de Dewey}

Desde la visión pragmatista del filósofo estadounidense John Dewey, la democracia es una lucha incansable por la libertad y la igualdad. Por lo tanto, la democracia participativa la plantea desde un enfoque que tiene como base fundamental la educación cívica. En este sentido converge con las ideas de la filósofa española Camps (2010: p. 15), quien sentencia parafraseando a Aristóteles: "de nada sirven las leyes más útiles, aún ratificadas unánimemente por todo el cuerpo civil, si los ciudadanos no son entrenados y educados en el régimen". A partir de prácticas de convivencias plurales y pacíficas es posible construir un sistema de decisiones públicas maduro y sólido que sea eficaz en la conducción de la vida comunitaria. Para Dewey, la democracia consiste en un proyecto ético político, un modo de vida personal y colectiva que se debe incorporar concretamente en las prácticas cotidianas. Es precisamente a partir de esta concepción que se puede apreciar el vínculo teórico entre gobernanza democrática y participación a través del capital social que destacamos en este estudio. De acuerdo con Aguilera (2009, p 64), "Dewey ve en la democracia moral exigencias que vinculan a los individuos y a los grupos.

La sociedad es un entramado de relaciones intersubjetivas, donde los individuos son resultados, productos y agentes participantes de este enjambre social. De este modo, a los individuos se les puede exigir participar según su capacidad y sus necesidades en la actividad y en los valores del grupo". Más adelante el propio Dewey al destacar el valor moral de la democracia, nos ofrece su coincidencia con la perspectiva institucional que muchos años después perfeccionaría Douglass North y que también guarda una estrecha relación con el capital social. Si la democracia tiene un significado moral, éste consiste según Dewey en que "... establece que la prueba suprema de todas las instituciones políticas y todos los dispositivos de la industria está en la contribución de cada una de ellas al desarrollo acabado de cada uno de los miembros de la sociedad". El filósofo norteamericano considera a la democracia como un reflejo de la educación cívica que debe estar presente en las prácticas cotidianas del ciudadano; un ideal de vida comunitaria. Por lo tanto, concibe la moral como consecuencia de esa práctica fundada en el valor supremo de desarrollar nuestras capacidades y las de la colectividad a partir de problemáticas concretas generadas en la propia realidad y que dan oportunidad de generar los aprendizajes individuales y colectivos que enriquecen el desarrollo social. Finalmente sentencia: "Una sociedad es democrática en la medida en que facilita la participación en sus bienes de todos sus miembros en condiciones iguales y que asegura el reajuste flexible de sus instituciones mediante la interacción de las diferentes formas de vida asociada". Podemos apreciar como involucra no solamente a individuos, sino que enfatiza el rol de los grupos sociales. Así, por un lado, los individuos deben participar según su capacidad en la actividad y valores del grupo y por otro, los grupos deben liberar y ayudar a desarrollar todas las potencialidades de los individuos de acuerdo con el interés de la comunidad.

\section{La participación ciudadana, fundamento de la legitimidad democrática}

La legitimidad es la piedra angular del modelo democrático. Si los valores son la igualdad y la libertad, la legitimidad es su condición funcional. De manera general, decimos que una cosa o situación es legítima cuando se considera justa, relacionada con la justicia. En sentido estricto (Levi: 2013: p. 862.) a la política se refiere "a un atributo del Estado que consiste en la existencia en una parte relevante de la población de un grado de consenso tal que asegure la obediencia sin que sea necesaria (...) recurrir a la fuerza". Por lo tanto, se requiere un alto nivel de consenso para que a un gobierno se le considere como legítimo. En este sentido, la legitimación se presenta como una necesidad que tiene la autoridad por obtener el consenso. Sin 
embargo, hay suficiente evidencia de que la manipulación del consenso existe también en los regímenes democráticos (Levi, 2013, pág. 865). Los tipos de modelos más conocidos de legitimidad son los propuestos por Max Weber y por Karl Deutsch. El primero (Weber, 1970) nos propone tres tipos de legitimidad en función del origen de la autoridad; 1) la legitimidad tradicional, fundada en las costumbres y tradiciones arraigadas en la comunidad; 2) la carismática; sustentada en las cualidades y virtudes del líder; y 3 ) la formal o racional, que se basa en las normas establecidas y del derecho que de éstas derivan. Por su parte, Deutsch nos propone tres tipos de legitimidad según ciertas circunstancias (Política y Gobierno, págs. 27$29) ; 1)$ Por procedimiento, se refiere a la forma en que se accede al poder en un gobierno, es decir al nivel de aceptación y compatibilidad que los gobernados tienen respecto al gobernante y a su forma de acceso al puesto; 2) Por representación, en función de la delegación de poder que, a través de la designación de los representantes, los electores transfieren a sus gobernantes; y 3) Por resultados. Se refiere sobre todo a lo que se hace en la política, es decir además del principio de racionalidad y de representación, apela a la compatibilidad de lo que el gobierno hace, las políticas respecto a lo que la comunidad desea, espera y valora. Así, la legitimidad racional, por delegación y por resultados se complementan para configurar ese consenso que evita que se califique a un gobierno como ilegítimo, con lo cual se corre el riesgo de violentar la estabilidad del régimen o degenerar en una tiranía, una revolución e en otra forma de rompimiento del conjunto social (Deutsch, pág. 28).

En los sistemas políticos modernos es la representación la forma en la cual la participación política se traduce en gobierno, en decisiones, en acciones y en políticas públicas. En un primer momento se conforma en las decisiones que mediante los procesos legislativos se convierten en decretos, leyes, programas, políticas lineamientos que prefiguran la gestión pública. En un segundo momento esta representación se convierte en acción mediante la gestión pública que convierte esas decisiones en bienes y servicios que ininterrumpidamente intentan satisfacer las exigencias y demandas de la sociedad procurando su progreso y desarrollo social.

No obstante, si bien la participación es una demanda latente por parte de la sociedad, ésta no siempre se materializa si no se cuenta con un sistema político adecuado (Instituciones representativas y partidos políticos). En este sentido, debe considerarse que la representación tanto en el legislativo como en el ejecutivo debe darse con compromiso, transparencia y sencillez. No se puede esperar una participación ciudadana libre, consciente e informada cuando el lenguaje de las autoridades es demagógico (retórico) y/o encriptado (sumamente rebuscado), o cuando no se ofrecen medios efectivos para participar en la elaboración y ejecución de las decisiones. Y sin estas premisas, de conformidad con los criterios que nos propone Dahl, es imposible hablar de gobiernos democráticos modernos ${ }^{3}$.

La participación requiere por parte del ciudadano la credibilidad en el gobierno por lo menos en tres aspectos: 1) Que se considere verdaderamente democrático (legitimidad), 2) Que el proceso sea honesto, es decir con plena transparencia de los actores al momento de intervenir en éste; y 3) Que sea eficiente, que no represente altos costos ni a las entidades públicas ni a los ciudadanos. Representativo a todos los niveles, descentralizado y defensor decidido de las libertades de la sociedad. Honesto y eficiente en todas las administraciones públicas, transparente en su funcionamiento y gasto, flexible y dialogante en su relación con la ciudadanía. Es en este marco en el cual se abren las posibilidades para fortalecer la democracia mediante el impulso del gobierno abierto.

En efecto, la descentralización efectiva del Estado (consolidando y creando entes regionales, locales y barriales con competencias y recursos) y la modernización del gobierno (no para eliminar la gestión pública

3 Ver supra, p. 7. No se cumplen los criterios relativos a la participación, la comprensión ilustrada y el control de la agenda que propone este autor en su modelo democrático.

Revista Política, Globalidad y Ciudadanía, Vol. 4 No. 7, Enero - Junio 2018, Universidad Autónoma de Nuevo León, Monterrey, México, ISSN 2395-8448. pp 14-30. http://revpoliticas.uanl.mx/index.php/RPGyC/article/view/86 
sino para hacerla más productiva, competitiva frente a proveedores alternativos de servicios públicos) son requisitos para implementar la participación democrática.

\section{La participación y el gobierno abierto}

La actual situación de escasez de recursos públicos y de mayores demandas sociales en las localidades de base (la necesidad de reactivación económica y de la creación de empleos; las demandas de seguridad pública; de salud; de educación; de construcción y rehabilitación de vivienda; vialidad y transporte público, entre otros) ofrece la participación como una alternativa para movilizar los recursos potenciales latentes en la colectividad mediante la cooperación y la solidaridad social. Sin embargo, esta participación no sustituye la opacidad, la ineficacia, la insensibilidad y la baja productividad de un gobierno, sino que una gestión pública justa y activa y unos programas ambiciosos e innovadores que contribuyan al mejoramiento de las condiciones de vida de la ciudadanía, son condiciones previas para el desarrollo de la participación.

La participación se basa en el contenido material de ésta, es decir, en expectativas fundadas de progreso individual y colectivo, pero también en que exista un conjunto de mecanismos institucionales y que se reconozcan estos derechos ejercitables. Y son las mayorías populares y marginadas las que más necesitan esta institucionalización.

La regulación de los derechos difusos (consumo, urbanismo, medio ambiente, comunicación social, servicios públicos, etc.) mediante las cartas al ciudadano; la participación en la elaboración y ejecución de programas de actuación pública; la autogestión de servicios con el apoyo de la Administración; la intervención de la democracia de base en las instituciones representativas (Derecho de Audiencia Pública, Comisiones Mixtas, etc.) son aspectos pendientes de la agenda participativa en los diferentes ámbitos de gobierno. Todos ellos se ven potenciados mediante el modelo de gobierno abierto.

Se deben fortalecer los espacios públicos y a los interlocutores colectivos para potenciar la participación. Si bien éstos ya existen, (organizaciones sociales, cívicas, sindicales, culturales, ambientales, de interés común, entre otras) tienen características y fortalezas distintas. Unos se distinguen por su representatividad, otros por sus iniciativas, otros por su capacidad de gestión y organización. Por otra parte, hay que considerar las intervenciones individuales y espontáneas que derivan de la interactuación entre ciudadano y gobierno a través de la administración pública. En todo caso, es necesario establecer el equilibrio entre la participación pública y la participación de la sociedad civil de conformidad con la naturaleza de la intervención social y de la propia organización.

La voluntad de un gobierno participativo se manifiesta por el apoyo que brinda a las organizaciones sociales locales y/o nacionales sin exigir ningún tipo de dependencia administrativa o partidaria. La participación debe considerarse un método de gobierno, un estilo de hacer política en el estado, en y con la sociedad, que supone cumplir con los requisitos previamente señalados: la racionalización de la gestión pública y la descentralización de las políticas de estado. La cultura democrática se desarrolla en un contexto dialéctico de pluralismo y consenso, de confrontación y de negociación, que sólo puede ofrecer un estado descentralizado y participativo, en un contexto de gobernanza.

Por su parte, Kliksberg (2001) nos propone seis tesis que justifican la participación ciudadana y que, a su vez, nos muestran el papel que ésta juega en el gobierno abierto:

1. La participación genera resultados. En la esfera social, la participación ciudadana produce resultados muy superiores a otros modelos tradicionales de organización, incluyendo los de tipo burocrático y paternalista.

2. La participación tiene ventajas comparativas. Los proyectos de infraestructura cuando se organizan alrededor de la participación intensa de la comunidad, permite alcanzar metas que van más allá de

Revista Política, Globalidad y Ciudadanía, Vol. 4 No. 7, Enero - Junio 2018, Universidad Autónoma de Nuevo León, Monterrey, México, ISSN 2395-8448. pp 14-30. http://revpoliticas.uanl.mx/index.php/RPGyC/article/view/86 
los propósitos directos de las obras y proyectos. Se podrían denominar los "meta o supra objetivos". Entre ellos los siguientes:

- Eficiencia y productividad: es decir, el uso óptimo de recursos escasos.

- Equidad: en términos de la distribución igualitaria y permanente entre diversos sectores de la comunidad de los beneficios de un proyecto.

- Sostenibilidad: significa la prolongación de la vida útil y los beneficios de un proyecto en el largo plazo.

Estas ventajas comparativas arrojan, en conjunto, resultados superiores a los modelos burocráticos o paternalistas que se organizan de arriba abajo.

3. La participación contribuye a mejorar la gerencia pública y la administración.

4. La participación enfrenta resistencias e intereses poderosos.

5. Para fortalecer la participación se requieren políticas y estrategias activas. La idea subyacente es reemplazar la democracia pasiva por una democracia activa, inteligente y viva. En esta última habría canales abiertos de comunicación para que el ciudadano se mantenga bien informado; para que pueda hacer llegar su opinión a las instituciones políticas por diversos medios, no únicamente los días de votación; para lograr una influencia continua y genuina sobre la administración pública.

6. La participación es inherente a la naturaleza humana. Es un fenómeno que "eleva la dignidad humana y crea la posibilidad de desarrollo y realización. Trabajar a favor de la participación es, sin duda, devolver un derecho fundamental a los marginados...".

En suma, podemos afirmar con Pichardo Pagaza (2004) que la participación ciudadana es una pieza clave en la legitimidad y en la gestión eficaz de políticas públicas por lo cual debe en todo momento estar en la voluntad política de todo gobernante que se reclame como democrático.

La participación ciudadana, el espacio público y el gobierno abierto

7. Reconociendo que la legitimidad democrática trasciende la participación electoral, la democracia representativa y la democracia procedimental, entonces el reto se plantea a nivel del funcionamiento del gobierno, es decir de la propia gestión pública. Esto implica que los gobiernos deben concebirse como plataformas de democracias participativas cuyos elementos constitutivos son la transparencia, la rendición de cuentas, y la colaboración de ciudadanos con las administraciones públicas apoyados en las tecnologías de información y en un modelo de gestión basado en la ética y la confianza (Mariñez Navarro, pág. 45). En este sentido, la evolución de la participación ciudadana se inserta en la agenda de la administración pública y en la misma medida contribuye al fortalecimiento de la democracia a través del gobierno abierto. Ello es evidente en las consideraciones teóricas que se han enfocado en el tema de la participación ciudadana en reuniones y cumbres internacionales (Sánchez González, pág. 57), pero también en la legislación que ha venido ampliando los mecanismos y espacios de comunicación entre ciudadanos y gobiernos, y que se ha reflejado en nuestro país a nivel nacional y local dando mayor relevancia a la participación ciudadana en el gobierno.

\section{Gobierno abierto en México}

El concepto de gobierno abierto tiene sus orígenes en el siglo pasado en un artículo de Wallace Parks titulado Open Governement (1957) en el cual este autor se refiere a la necesidad de reducir la opacidad en el gobierno y favorecer la publicidad de la información. Medio siglo después, el concepto resurge en la agenda internacional con el Memorandum de Barack Obama sobre transparencia y gobierno abierto de enero de 2009. Como consecuencia de ello, se consolidad el tema en la agenda gubernamental con la iniciativa del mismo Obama sobre la Alianza para el Gobierno Abierto de septiembre de 2011, a la cual se adhieren 8 países: Brasil, Indonesia, México, Noruega, Filipinas, Sudáfrica, Reino Unido y Estados Unidos. A partir de 
esta iniciativa se diseña en nuestro país el primer Plan de Acción promovido originalmente por la Secretaría de la Función Pública y algunas organizaciones de la sociedad civil. El plan incluía 18 compromisos, sólo uno de la sociedad civil por lo cual no fue muy bien recibido por parte de este sector. Por ello, se propuso la creación de un Secretariado Técnico Tripartita, (STT) como órgano de gobierno de la AGA México, conformado por una representación en igualdad de condiciones y poder de decisión de las tres partes involucradas: el Poder Ejecutivo, el Instituto Nacional de Transparencia, Acceso a la Información Pública y Protección de Datos Personales(INAI) y las OSC. Como resultado de esta instancia, se formuló un Plan de Acción Ampliado con 36 propuestas y compromisos siendo los más numerosos los referidos al manejo eficiente y eficaz de los recursos.

De acuerdo a un estudio realizado en 2015, los avances en México eran pobres y limitados. En el ranking sobre GA efectuado por el Proyecto Mundial de Justicia (WPJ), México alcanzó una calificación de .56 sobre .100; ocupo el lugar 42 entre 102 países en el Índice de Gobierno Abierto, y el sexto lugar de 19 países de América Latina. Según este índice la mejor posición de nuestro país fue en el ejercicio del derecho a la información, en el que se ubicó en el lugar 29; en mecanismo de queja alcanzo el sitio 34; en legislación y datos de gobierno fue el número 64 y en participación cívica se posicionó en el 67 (Bautista Farías, 2016). A partir de entonces, debido a diversos acontecimientos relacionados con actos de corrupción que estremecieron al gobierno federal y varios estatales (ODERBRECH, La estafa Maestra, La Casa Blanca, entre otros), los avances en materia de gobierno abierto fueron prácticamente nulos, con excepción de algunos avances realizados a nivel local.

\section{Conceptualización de Gobierno Abierto}

Son más las discordancias que los acuerdos cuando se habla de Gobierno Abierto. Para muchos significa cambio tecnológico más participación y colaboración ciudadana, para otros consiste en una nueva forma de gobernar, por lo cual implica un modelo de gestión pública más aun una nueva cultura de gestión que genera cambios en procesos, en las organizaciones públicas y en las relaciones, fortaleciendo las capacidades del gobierno y la modernización de la administración pública. En este sentido se inscribe la concepción de Insulza (Insulza, 2012, pág. 9), que sostiene que GA es una política pública que incluye la transparencia, participación y colaboración de los ciudadanos en donde la información y los datos gubernamentales desempeñan un papel esencial. Los países que integran la Alianza por el Gobierno Abierto coinciden en sus cuatro principios constitutivos que son indivisibles: la transparencia, la participación ciudadana; la rendición de cuentas y las tecnologías e innovación. En muchos casos, las críticas al concepto se centran en que es tendencialmente prescriptivo ya que se refiere a un deber ser sin que opere realmente en la forma en que se concibe.

Por nuestra parte, coincidimos en que se debe entender como un modelo de gobierno y de gestión que impacta de forma sustancial y simultánea el modelo político y el quehacer administrativo, potenciando las capacidades gubernamentales, y mejorando la eficiencia y la eficacia institucional a través del uso de los tics y de la transferencia y reutilización de datos e información pública entre ciudadanos y organizaciones públicas. Por otra parte, refuerza la vitalidad democrática al reforzar la transparencia y la rendición de cuentas. La transparencia resulta una dimensión clave para el Gobierno Abierto, ya que la visibilidad y publicidad del gobierno son premisas fundamentales de la democracia y el acceso de los ciudadanos a la información es condición de una rendición de cuentas responsable y oportuna. Ambas dan apertura a la participación y extienden las posibilidades de que la administración pública sea aceptada como un sistema de interacción y comunicación para fortalecer el principio de publicidad en favor de los gobernados. Es, por lo tanto, una cualidad del poder democrático que permite la ampliación de la legitimidad (Uvalle Berrones, 2007, pág. 46) Ya mencionaba Bobbio que una de las promesas incumplidas de la democracia era precisamente la visibilidad del poder. En pleno siglo XXI todavía enfrentamos opacidad en la toma de decisiones gubernamentales y en los procedimientos de la gestión pública. Es a través del GA que tenemos la opor-

Revista Política, Globalidad y Ciudadanía, Vol. 4 No. 7, Enero - Junio 2018, Universidad Autónoma de Nuevo León, Monterrey, México, ISSN 2395-8448. pp 14-30. http://revpoliticas.uanl.mx/index.php/RPGyC/article/view/86 
tunidad de ampliar el horizonte democrático desde la administración pública. Insulza percibe claramente esta oportunidad describiendo los impactos del GA al permitir la participación ciudadana en las decisiones públicas (Insulza, pág. 10), iniciar la interacción ciudadano-gobierno más colaborativa mediante el internet, fomentar la transparencia y promover la rendición de cuentas. En este aspecto, para algunos especialistas puede ser considerado como un modelo de reingeniería de la vida democrática de la sociedad en red, ya que fortalece la democracia participativa, vincula a los tomadores de decisiones con los ciudadanos, posibilita las decisiones en función de preferencias y opiniones, genera valor público mediante la co-creación, aprovechando el empoderamiento ciudadano (Bojorquez 2012: 175).

Desde la perspectiva de la gestión y la función gubernamental, Oszlak destaca varios elementos que inciden en las relaciones ciudadano, gobierno y los resultados de este último. En primer lugar, la facilitación que la tecnología ofrece para la comunicación e interacción recíproca entre ciudadanos y gobierno; en segundo, los canales que tiene el gobierno posibilitan la contribución de los ciudadanos en la toma de decisiones mediante las opiniones ofrecidas sobre las políticas públicas, pero también en el seguimiento, control y evaluación de los resultados de la gestión pública y, en tercer lugar, el involucramiento ciudadano en la responsabilización en estos nuevos roles colaborativos. La clasificación de las acciones emprendidas por los diferentes gobiernos durante los últimos años ofrece una amplia gama de propósitos subyacentes en estas acciones. Este es el esquema identificado por el estudio de Oszlak (Oszlak \& Kaufman, 2014, pág. 7): 1. Ampliar la información Pública disponible para la ciudadanía; 2. Garantizar y mejorar el ejercicio del derecho a la información pública; 3 . Mejorar el acceso a los servicios públicos y sus canales de entrega; 4 . Proteger los derechos de usuarios y funcionarios; 5 . Incrementar la transparencia en la gestión pública; 6 . Promover la participación ciudadana en la gestión gubernamental; y 7. Aumentar la capacidad institucional para una gestión abierta.

En estas argumentaciones observamos que el proceso participativo y el resultado de éste es influir en la gestión pública como protagonista y no solamente como receptor de bienes y servicios. Por lo tanto, afirma Oszlak (2014, pág. 26), trasciende con mucho el proceso de consulta pública. Mediante el proceso de información, intercambio, consulta de datos y la participación del ciudadano y de organizaciones de la sociedad civil, como interlocutores en el diseño e implementación de las políticas públicas, se democratiza la gestión pública. Esta constituye a nuestro parecer la contribución más importante del modelo de gobierno abierto al sistema democrático moderno. Por lo tanto, se requieren nuevas estrategias que amplíen las posibilidades de participación activa y los espacios públicos para que la colaboración ciudadano-gobierno se traduzca en mejores gobiernos, eficientes, transparentes, sujetos a la rendición de cuentas y al estado de derecho, y con una mayor legitimidad sustentada en los resultados de su gestión. Es así que se arriba a la democracia deliberativa.

\section{Gobierno Abierto y Democracia deliberativa}

De acuerdo con el análisis de las acciones arriba mencionadas en el estudio de Ozslak y Kaufman sobre Gobierno Abierto, en nuestra opinión, el rubro que mayormente incide en la democracia deliberativa es el referido a Promover la participación ciudadana en la gestión estatal. Incluso así lo afirma expresamente el autor en cuestión cuando subraya que "la participación ciudadana otorga a los gobiernos una pátina de legitimidad que mejora las condiciones de gobernabilidad y constituye un paso positivo hacia la construcción de una democracia deliberativa" (pág. 26). El fundamento en el que basan su argumentación es la Carta Iberoamericana de Participación Ciudadana en la Gestión Pública, aprobada por el CLAD en 2009 y adoptada por la XIX Cumbre Iberoamericana de Jefes de Estado y de Gobierno, en la cual se reconoce plenamente el derecho de la ciudadanía a intervenir activamente en las diferentes fases de la gestión pública. El documento, afirma Ozslak, sostiene implícitamente, que los pilares de una democracia plena son los derechos de información, participación, asociación y expresión sobre lo público, es decir "el derecho genérico de las personas a participar en la gestión pública colectiva e individualmente". Y estos principios, 
valores que plantea la Carta, y los elementos que constituyen las premisas de gobierno abierto, a saber: acceso a la información, transparencia, participación, colaboración, se corresponden totalmente. Esto nos permite afirmar que es precisamente la participación el elemento crítico que tanto desde la perspectiva de la democracia, como de la conceptualización y la práctica del Gobierno Abierto lo que da contenido a la esencia de ambas categorías. No se puede concebir la democracia sin la participación como tampoco se puede entender el gobierno abierto sin la participación ciudadana en la gestión pública. Esto se traduce en la trascendencia de una democracia deliberativa a una democracia colaborativa. Una prueba de ello es precisamente el último eje de las acciones del gobierno abierto descritas por el estudio de Oszlak que se orienta a aumentar la capacidad institucional para una gestión abierta.

\section{3.- MÉTODO}

Diseño

El enfoque investigativo de la presente investigación es cualitativo, de acuerdo con Hernández, Batista y Fernández (2014) “Utiliza la recolección y análisis de los datos para afinar las preguntas de investigación o revelar nuevas interrogantes en el proceso de interpretación” (p.7).

Alcanzando un diseño no experimental "Que se realiza sin la manipulación deliberada de variables y en los que sólo se observan los fenómenos en su ambiente natural para después analizarlos" (Hernández, Batista y Fernández, 2014, p. 149).

El alcance establecido es el exploratorio "emplean cuando el objetivo consiste en examinar un tema poco estudiado o novedoso” (Hernández, Batista y Fernández, 2014, p. 91).

\section{Instrumentos}

Para la construcción del marco teórico-conceptual del tema de la democracia participativa al gobierno abierto: hacia una delimitación conceptual, se consultaron un total de veintiún referencias bibliográficas utilizándose como instrumento las ideas, argumentos y proyectos que fueron interpretados desde una perspectiva analítica y crítica.

Procedimiento

Con relación a la comprensión del problema de la investigación se recopilan fuentes secundarias de documentos académicos. En el marco de referencia se definen los conceptos básicos en relación a Democracia y participación ciudadana. Una vez recopilada y analizada la información se construye el documento objeto de este trabajo. Por último, se realizan las recomendaciones y conclusiones conforme a los objetivos trazados (Bascón et al, 2016, p. 39).

\section{4.- CONCLUSIONES}

Las transformaciones económicas, sociales y tecnológicas han provocado reformas trascendentales en el modelo de gobierno, afectando de esta manera el funcionamiento de las democracias modernas. Una consecuencia evidente de ello ha sido la emergencia del gobierno abierto. Como hemos tratado de exponer en el presente trabajo el gobierno abierto se puede describir como un enfoque aglutinador de esfuerzos por mejorar las capacidades del gobierno y modernizar las administraciones públicas bajo los principios de la transparencia y apertura, de la participación ciudadana en la gestión pública y la colaboración entre gobernantes y gobernados en las políticas públicas.

De conformidad con nuestra hipótesis podemos afirmar que el modelo de gobierno abierto contribuye al fortalecimiento del modelo democrático ya que permite incentivar la participación ciudadana y a través de la accesibilidad de datos, de su política de transparencia y del desarrollo de plataformas y canales de comunicación con la población, ampliando los espacios públicos. De esta forma, abona a desarrollar el juicio

Revista Política, Globalidad y Ciudadanía, Vol. 4 No. 7, Enero - Junio 2018, Universidad Autónoma de Nuevo León, Monterrey, México, ISSN 2395-8448. pp 14-30. http://revpoliticas.uanl.mx/index.php/RPGyC/article/view/86 
político ciudadano sobre los problemas públicos y la forma de resolverlos, abriendo así las posibilidades de colaboración y co-creación de valor público. Por lo tanto, cuantos más ciudadanos estén implicados en este proceso, mayor será la fortaleza de la democracia, mejor funcionará el sistema, mayor será su legitimidad e igualmente, mayor su capacidad para controlar al gobierno e impedir abusos de autoridad y corrupción. En este sentido y partiendo de la premisa que en la democracia siempre debe de asegurarse el control del ciudadano sobre los gobernantes, todos los componentes del modelo contribuyen a fortalecer este proceso de control. El control del poder es una condición de la democracia que requiere instituciones que faciliten una mejor comunicación entre las administraciones públicas y los ciudadanos. Transparencia, rendición de cuentas y evaluación ciudadana son procesos que permiten que los ciudadanos tengan oportunidad de conocer qué, cómo, con qué, porqué el gobierno y la administración pública hacen lo que hacen y asi se puede evitar el abuso, la arbitrariedad y la corrupción. En este sentido, con un gobierno de ciudadanos que cuentan con medios para monitorear efectiva y oportunamente la gestión pública, nos acercamos verdaderamente a la democratización de la administración pública. Hacia allá nos conduce el gobierno abierto.

En fundamento a estas argumentaciones, podemos concluir que la hipótesis y la premisa formulada al inicio de documento se constatan en la medida en que un gobierno democrático debe tener como ejes los elementos que forman el andamiaje institucional del gobierno abierto: acceso a la información, transparencia, rendición de cuentas, colaboración en la gestión pública, predictibilidad y mejora de la gestión. En función del desarrollo de las dos vertientes fundamentales de un gobierno abierto se fortalecerá la democracia colaborativa. Estas vertientes son: por una parte, la apertura de datos públicos, que pretende la transparencia y una mayor eficiencia en el servicio público, permitiendo reutilizar los datos públicos para nuevas actividades económicas y la rendición de cuentas ante los ciudadanos; y por la otra, la apertura y desarrollo de medios sociales y espacios públicos, que procuran facilitar la comunicación entre gobierno y ciudadanos y la participación ciudadana, aprovechar el conocimiento y experiencia de los ciudadanos para ayudar en los provisión de los servicios públicos, la colaboración en redes internas y entre dependencias y entidades de las administraciones públicas.

\section{REFERENCIAS}

Abramovitch, V. (Abril 2006). Una aproximación al enfoque de derechos en las estrategias y políticas de desarrollo. Revista de la Cepal No 88 .

Aguilar Villanueva, L. (2007). Aporte de las Políticas Públicas y la Nueva Gestión Pública a la Gobernanza. CLAD Reforma y Democracia No 39, 1-15.

Aguilera Portales, R. (2009). El debate entre democracia directa y democracia participativa: hacia una democracia de mínimos. En R. Aguilera Portales, La democracia del Estado Constitucional (pág. 205). México: Porrua-UANL-CEP.

Bascón, M.: Cazallo, A.; Lechuga, J. \& Meñaca, I. (2016). Estudio de la necesidad de implantar un servicio público de transporte entre las ciudades de Ceuta-Tetuán y Melilla-Nador. En Desarrollo Gerencial Revista de la Facultad de Ciencias Económicas, administrativas y contables de la Universidad Simón Bolívar 8(2), $37-57$.

Bobbio, N. (1999). El Futuro de la democracia. México: FCE.

Borja, J. (Febrero 2002). Ciudadanía y globalización. CLAD, Revista Reforma y Democracia N. 22 .

Bovero, M. (Abril 1998). Los Verbos de la Democracia. Este País No 263.

Bovero, M. (2002). Una gramática de la democracia. Madrid: Trotta.

Cerroni, U. (1991). Reglas y valores de la democracia. Mexico DF: Alianza.

Revista Política, Globalidad y Ciudadanía, Vol. 4 No. 7, Enero - Junio 2018, Universidad Autónoma de Nuevo León, Monterrey, México, ISSN 2395-8448. pp 14-30. http://revpoliticas.uanl.mx/index.php/RPGyC/article/view/86 
Cunill Grau, N. (2008). La construcción de ciudadanía desde una institucionalidad ampliada. En R. C. Mariani, Democracia/Estado /Ciudadanía: Hacia un Estado de y para la democracia en AL (págs. 113-135). Lima: PNUD.

Dahl, R. (1999). La democracia. Una Guía para los ciudadanos. Buenos Aires, Argentina: Taurus.

Deutsch, K. (1973). Política y gobierno. México: FCE.

Díaz- Albertini Figueras, J. (2011). Capital Social, organizaciones de base y el Estado. En CEPAL, Capital Social y reducción de la pobreza en América Latina y el Caribe. Santiago.

Gómez, C. e. (2012). Problemas Éticos del Mundo Actual. México: Delaurel.

Hernández, R., Fernández, C., y Baptista, P. (2014). Metodología de la investigación. México: Mc Graw Hill.

Kliksberg, B. (2001). Towards an Intelligent State. New York: UNDESA-IIAS.

Marshall, Tomas. (1997). Ciudadanía y clase social. Reis. 79/97. Traducción de Ma. Teresa Casado y Francisco Javier Noya Miranda.

Pichardo, I. (2004). Modernización Administrativa:Propuesta para una reforma inaplazable. Toluca: Colegio Mexiquense-UNAM.

Puyol, A. (2010). Los deberes del ciudadano con la humanidad. En V. Camps, Democracia sin ciudadanos (pág. 198). Madrid: Trotta.

Sen, A. \&. (2007). Primero la Gente. Barcelona: Deusto.

Uvalle Berrones, R. (2011). Las políticas públicas en el arquetipo de la gobernanza. Reforma y Democracia No $50,1-13$. 